\title{
Globe
}

Revue internationale d'études québécoises

\section{Repenser le pays}

\section{Daniel Chartier}

Volume 4, numéro 1, 2001

Repaysements du Québec

URI : https://id.erudit.org/iderudit/1000598ar

DOI : https://doi.org/10.7202/1000598ar

Aller au sommaire du numéro

Éditeur(s)

Globe, Revue internationale d'études québécoises

ISSN

1481-5869 (imprimé)

1923-8231 (numérique)

Découvrir la revue

Citer ce document

Chartier, D. (2001). Repenser le pays. Globe, 4(1), 9-9.

https://doi.org/10.7202/1000598ar d'utilisation que vous pouvez consulter en ligne.

https://apropos.erudit.org/fr/usagers/politique-dutilisation/ 


\section{Présentation \\ Repenser le pays}

Construit autour de l'idée lancée par Hubert Aquin du " repaysement ", ce numéro propose une relecture du Québec qui s'articule de plusieurs manières, mais qui toutes rejoignent une volonté de saisir la réinvention du pays.

En ouverture, Brigitte Faivre-Duboz étudie les positions prises par deux grands intellectuels québécois des années soixante, Hubert Aquin et Pierre Elliott Trudeau, qui ont tous deux inscrit leur réflexion dans une pratique du politique certes différente, mais déterminante pour l'avenir du Québec.

Sandrina Joseph propose une lecture de l'éclatement identitaire dans La Québécoite de Régine Robin, un roman-phare de l'écriture migrante, alors que Louis-Jacques Dorais étudie les notions de "déplacement sur le territoire" (maqainniq en inuktitut) et de "moyens de faire de l'argent "(kiinaujaliurutiit) dans le village inuit de Quaqtaq, au Nunavik. Quant à Thomas C. Spear, il retrace l'évolution de l'usage de la langue anglaise chez les écrivains québécois francophones, tandis que Jean-François Hamel analyse les rapports conflictuels entre la mémoire et l'enfance dans la littérature québécoise.

En études libres, Éric Montpetit et Christian Rouillard répliquent, dans un article scientifique, aux "discours réactionnaires sur l'étatisme et le néo-corporatisme québécois". Enfin, comme à l'habitude, le numéro se clôt sur les recensions et les parutions récentes en études québécoises.

Daniel CHARTIER directeur

GLOBE, Revue internationale d'études québécoises professeur département d'études littéraires Université du Québec à Montréal 